\title{
Processo PTA-P - Uma Revisão da Literatura como Base para Inovações. Parte 2 de 2: Comportamento Térmico e Cinemático do Pó, Parâmetros e Consumíveis do Processo
}

\author{
(PTA-P Process - A Literature Review as Basis for Innovations. Part 2 of 2: Powder Thermal and Kinematic Behavior, Process \\ Parameters and Consumables
}

\author{
Régis Henrique Gonçalves e Silval, Jair Carlos Dutral, \\ ${ }^{1}$ UFSC Departamento de Engenharia Mecânica / LABSOLDA - Instituto de Soldagem e Mecatrônica, Florianópolis, SC, Brasil \\ regis@labsolda.ufsc.br
}

\begin{abstract}
Resumo
A forma do material de adição confere ao processo PTA-P alguns de seus principais diferenciais de desempenho em relação ao processo com adição de arame. No campo metalúrgico, há maior flexibilidade de manipulação da composição química do depósito pela mistura de pós; o material particulado também favorece maior refino da microestrutura. Em termos de processo, o pó favorece maior controlabilidade da poça metálica e geometria do cordão. Por outro lado, o pó também é a origem de grandes desafios tecnológicos, principalmente em aplicações não convencionais, como na posição sobrecabeça. Assim, o estudo sobre o comportamento do pó em sua trajetória até a poça de fusão foi realizado, como base de conhecimento para inovações do sistema. São descritas as propriedades e processos de fabricação do material de adição e suas implicações sobre o processo. Também neste segundo artigo da série é apresentado um panorama dos parâmetros utilizados em trabalhos industriais e de P\&D relatados na literatura, sob diferentes condições e aplicações, incluindo regulagens elétricas e os parâmetros geométricos da tocha e alimentação de material. Com influência fundamental no resultado da solda, também os gases do processo são abordados.
\end{abstract}

Palavras-chave: Soldagem Plasma Pó, revestimento, soldagem fora de posição, alimentação de pó, fusão de pó

Abstract: The form of the filler material yields to the PTA-P Process some of its performance distinctions in relation to wire feed. In the metallurgical field, there is manipulation flexibility over the material, and therefore the deposit's chemical composition by means of powder mixture; in addition, greater grain refining is favored by the particulate material. In terms of process, one can mention better molten pool controllability and bead finishing from powder. On the other hand, particulate material consists also in the origin of technological challenges, mainly in non conventional applications, like overhead position welding. Hence, studies on the powder behavior in its way until the welding puddle was necessary as knowledge basis for process innovations. Also this second article of the series presents a panorama of the parameters used in $R \& D$ and industrial PTA-P works found in the literature, under different conditions and for different applications. This list comprises electrical adjustments geometric parameters of the torch and material feeding. Having a fundamental influence over the weld results, the process gases are approached as well.

Key-words: Plasma Powder Welding, coating, out of position welding, powder feed, powder melting

\section{Introdução}

Em seqüência ao primeiro artigo da série que apresenta de maneira crítica e com forte embasamento tecnológico, além dos fatores científicos, conhecimentos atuais acerca da Soldagem PTA-P, este segundo trabalho aborda aspectos ligados a peculiaridades do processo relativas à especial forma do material de adição suas propriedades e impactos sobre o processo, assim como parâmetros e gases aplicados.

Primeiramente, se trata do comportamento do material de adição, em termos de transporte, aquecimento, fusão e incorporação à poça metálica e formação do metal de solda. A natureza de forma do material, particulado, consiste num

(Recebido em 12/03/2012; Texto final em 14/06/2012). diferencial fundamental do processo em relação à técnica com adição de arame, sendo fonte ao mesmo tempo de vantagens e desafios atrelados ao PTA-P. Como benefícios metalúrgicos pode-se citar maior refino microestrutural $[1,2]$, versatilização de desenvolvimento de novas ligas pela flexibilidade de manipulação da composição química através da mistura de pós $[3,4]$ e realização de revestimentos compósitos nos quais se têm uma matriz metálica dútil e um material de alta dureza [5]. Já em termos de processo, a transferência suave de material, sem oscilações da poça (causadas pelas gotas metálicas em processos com arame de adição), ausência de respingos, independência entre energia e material de aporte e coaxialidade da injeção de material, permitem boa controlabilidade da poça de fusão e da geometria e acabamento do cordão. Por outro lado, o material particulado também é a origem de grandes desafios tecnológicos, principalmente em aplicações não convencionais, como a soldagem na posição sobrecabeça e/ou misturas de 
pós com diferentes propriedades físicas. Em assim sendo, é de significativa importância o entendimento dos fenômenos e influências que o material de adição pode sofrer desde a sua dosagem até a fusão e incorporação ao metal de solda. Esse conhecimento permite que se adéqüe o projeto de inovações, no sentido de possibilitar aplicações não convencionais para este processo.

No que tange à regulagem do processo, a primeira preocupação é uma adequada observação das diferenças entre os processos chamados Plasma. Muitas vezes equivocadamente descritas na literatura, as vantagens, propriedades e aplicações do PTA-P não se originam nas mesmas premissas que no caso do processo PAW. Este segundo surgiu como processo de união, em busca de maior concentração de energia e menor relação largura / profundidade de penetração. Já o PTA-P surgiu basicamente como um processo de revestimento, buscando, intrinsecamente, maior relação largura / penetração. Apesar de suas similaridades construtivas em relação à tocha, as supracitadas diferenças entre os dois processos levam a parametrizações distintas, que, se não levadas em consideração, inviabilizam o sucesso em sua aplicação.

Portanto, este segundo artigo da série visa apresentar um panorama do processo PTA-P, em aspectos de parametrização, consumíveis, comportamento do material de adição e respectiva formação do depósito, no intuito de contribuir para que se realizem abordagens tecnicamente mais adequadas tanto em trabalhos de pesquisa e desenvolvimento, como em aplicações industriais. Considera-se que a insuficiência de conhecimento sobre o processo em todas as suas variações e correlacionamentos incorretos com o processo PAW acabam por impedir a expansão de sua aplicação em operações nas quais poderia consistir em uma opção tecnológica de desempenho superior às realmente adotadas.

\section{Comportamento Térmico e Cinemático do Pó}

Algumas propriedades do processo PTA-P e dos resultados obtidos nos revestimentos são influenciados não somente pela

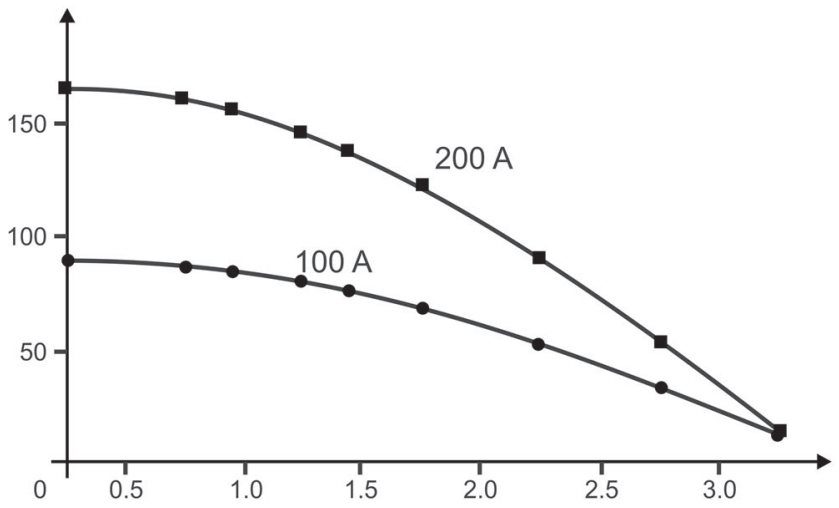

(a)

Distancia do eixo axial $(\mathrm{mm})$ composição química dos materiais, mas também pela dinâmica e comportamento térmico do pó em sua trajetória após sua ejeção da tocha. Uma avaliação teórica do transporte do pó e seu comportamento térmico dentro do arco foi realizada em diferentes trabalhos [2, 6-8] com resultados distintos. Em dependência do procedimento de soldagem, granulometria do pó e projeto da tocha, diferentes quantidades de pó são desviadas de seu trajeto desejado, alcançando ou não a poça de fusão. Fauchais e Vardelle [9] não avaliaram quantitativamente o comportamento do pó, como o fizeram Pavlenko, [2], Hongying et al. [6], Xibao e Wenyue [7], e Xibao et al. [10], mas mencionaram que o local de injeção, o estado de turbulência do gás e a quantidade de movimento vetorial das partículas em relação ao jato plasma influenciam sua aceleração e aquecimento. As colisões das partículas com as paredes do canal de injeção resultam em diferentes velocidades e trajetórias no ponto de injeção, contribuindo para diferentes tempos de permanência no plasma e diferentes evoluções tempo / temperatura ao longo da trajetória [9].

O ponto de partida para avaliação das características termocinéticas é a observação das propriedades do arco, que, por terem sua medição deveras complexa, são calculadas sob determinadas condições de contorno. A Figura 1a), adaptada do trabalho de Xibao et al. [7], mostra a velocidade do fluxo do plasma, em função da distância radial entre o ponto de análise e o eixo da coluna de plasma. Já a Figura 1b) mostra o resultado obtido por Hongying [6], com o diâmetro do bico constritor no eixo das abscissas.

Nota-se grande discrepância entre os valores de velocidade, por exemplo, para 100 A e diâmetro do orifício constritor de 6,0 $\mathrm{mm}$. Observa-se que os valores de vazão de gás de plasma $(0,25$ $1 / \mathrm{min})$ e vazão de gás de arraste de pó (0,4 1/min) assumidos por Xibao e Wenyue [7] estão fora da faixa verificada na experiência do LABSOLDA e na literatura (entre aprox. 1,0 1/min e 2,5 1/min para o gás de plasma e 2,0 1/min e 5,0 1/min pra o gás de arraste). Pavlenko [2] assume em seus cálculos uma velocidade de 160 $\mathrm{m} / \mathrm{s}$ para o fluxo do plasma, afirmando, ainda, que velocidades de jato plasma dessa ordem resultam em baixa pressão sobre a
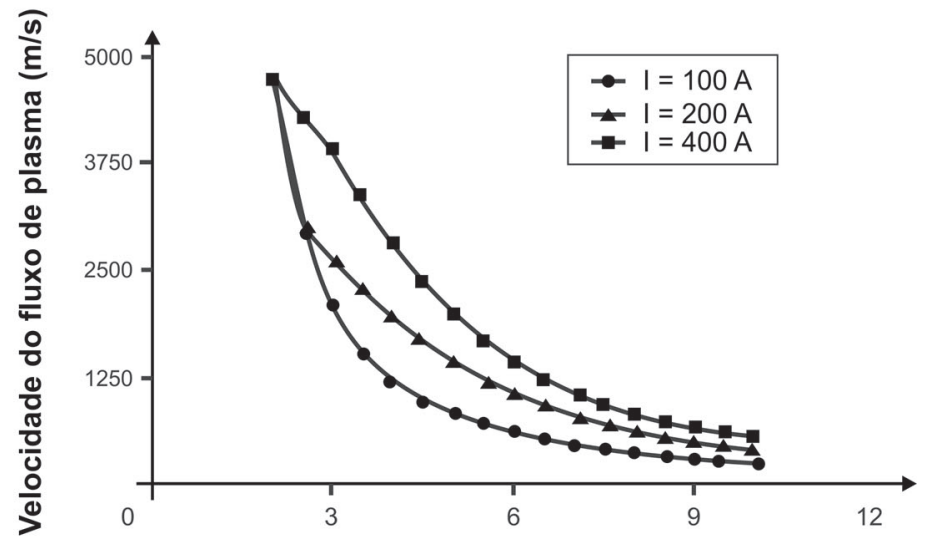

(b)

Diâmetro do bico constritor $(\mathrm{mm})$

Figura 1. Velocidade do Fluido Plasma: a) em função da distância do eixo axial da coluna do arco (adaptado do trabalho de Xibao et al. [7]); e b) entre velocidade do fluxo do arco, corrente e diâmetro do orifício constritor (adaptado do trabalho de Hongying et al. [6]) 


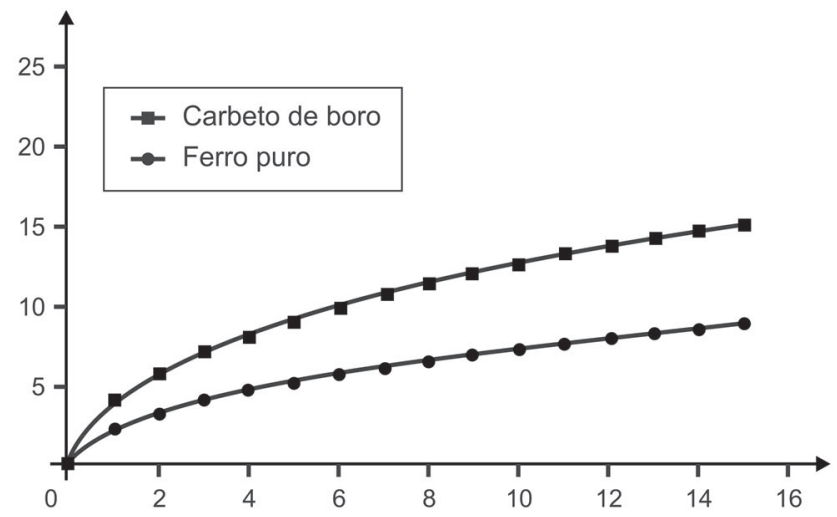

(a)
Distância do bico constritor $(\mathrm{mm})$

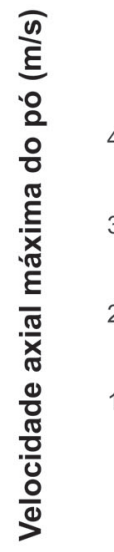

(b)

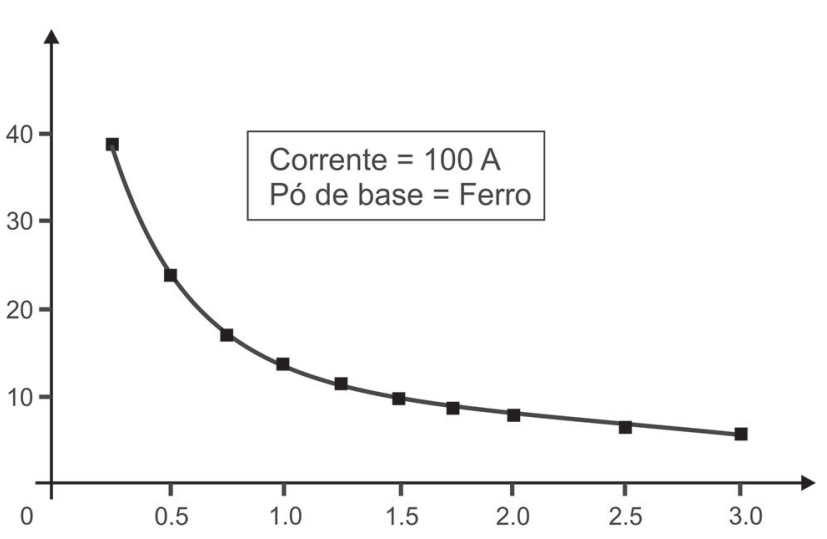

Diâmetro médio do pó $\left(10^{-4} \mathrm{~m}\right)$

Figura 2. a) Processo de aceleração de partículas de pó de diferentes densidades (Fe e $\mathrm{B}_{4} \mathrm{C}$, de menor densidade), para uma corrente de arco PTA-P de 100 A; b) velocidade do pó com diferentes diâmetros, para uma corrente de 100A (adaptado do trabalho de Xibao et al. [7])

poça e baixa penetração.

Xibao e Wenyue [7] também avaliaram a força que arrasta o pó, a qual depende da viscosidade do plasma. A viscosidade do plasma, por sua vez, varia com a temperatura, de maneira não linear. Como mostra a Figuras 2, a Vp (velocidade das partículas) é maior para partículas de menor densidade e menor diâmetro. Em [11] se atribui uma velocidade na injeção das partículas de cerca de $1,5 \mathrm{~m} / \mathrm{s}$ a $2,0 \mathrm{~m} / \mathrm{s}$ e em [2], $4 \mathrm{~m} / \mathrm{s}$.

A Figura 3 ilustra em a), a distribuição radial da velocidade das partículas em diferentes correntes de soldagem em decorrência do perfil de viscosidade, como calculado por Xibao e Wenyue [7] e, em b), o perfil de viscosidade, calculado por Schnick et al. [12] em simulação numérica do Plasma, mostrando coerência entre os trabalhos.

Nota-se que velocidade das partículas é substancialmente menor que a velocidade do plasma e que as máximas velocidades daquelas se dão num campo onde a temperatura está na faixa de $9000 \mathrm{~K}-11000 \mathrm{~K}$, no qual se tem maior viscosidade do plasma. Ainda segundo Xibao e Wenyue [7], para maiores correntes o efeito de vale é mais pronunciado (Figura 3). Percebe-se que isto pode ser levado em consideração no projeto de tochas, no que tange ao direcionamento de pós com diferentes propriedades para as regiões mais termicamente adequadas do arco.

Dentre as condições de contorno para cálculo, foi assumida uma condição de alimentação coaxial de pó ao arco (como a que ocorre no tipo de injeção interna) por Xibao e Wenyue [7] e injeção externa com dois orifícios, por Hongying [6]. Esta diferença provavelmente contribui para os valores de velocidade desiguais.

Ainda dentro deste aspecto, Pavlenko [2] concluiu que o aquecimento do pó não depende da velocidade do jato plasma, uma vez que os efeitos de aumento da eficiência de troca térmica entre o plasma e a partícula e menor tempo de permanência da segunda no primeiro com o aumento da velocidade do plasma se compensam. Segundo a mesma obra, há independência também entre o aquecimento da partícula e as propriedades termofísicas dela, pois a temperatura do plasma é enormemente maior que a temperatura alcançada pela partícula.

A partir dos resultados dos cálculos do comportamento do movimento das partículas de pó, Xibao e Hua [8] calcularam o tempo de viagem do mesmo pela região central do plasma, em uma DBP de $15 \mathrm{~mm}$, e, segundo os autores, a corrente não exerce significativo efeito sobre este tempo. Sob diferentes correntes, as condições de convecção e condução seriam responsáveis por diferenças no aquecimento do pó. Os autores calcularam, para diferentes diâmetros de partícula, o tempo para alcançar diferentes temperaturas e assim, determinar o estado alcançado pela partícula ao adentrar a poça. Em seus cálculos, consideraram correntes de 150 A e 200 A (Figura 4). Observa-se que a utilização de 200 A incorreria em perda de material por evaporação $(<75 \mu \mathrm{m})$, e até $153 \mu \mathrm{m}$, aconteceria fusão total. Em trabalho posterior, o mesmo autor, Xibao [10] e outros concluíram que a maior parcela para fusão completa das partículas vem, de fato, da poça metálica. Pavlenko [2] e empresa do setor de PTA-P [13], citam que a transferência de calor da poça para o pó exerce refrigeração da primeira, contribuindo para menor diluição obtida pelo PTA-P. Ademais, a superfície do pó se transforma numa frente de cristalização, permitindo estrutura anisotrópica e refinada (teoria defendida em [14] e verificada em [1], que comparou arame e pó).

$\mathrm{Na}$ verificação experimental de Xibao e Hua [8], pó de 150 mesh apresentaram dendritas finas na superfície. Submetido a um plasma de $80 \mathrm{~A}$, se verificou apenas coalescimento das dendritas, indicando a não fusão. Partículas submetidas a plasma de 120 A não apresentaram mais as dendritas, indicando que ao menos a superfície foi fundida.

Quanto à importância da velocidade das partículas, Hongying [6] afirma que maiores valores proporcionam maior facilidade de junção entre o material de base e o aportado. Podese supor que, quanto mais veloz, mais profundamente a partícula penetra na poça, melhor a absorção de calor adicional e menor a sua tendência a não se fundir completamente ou de não se incorporar ao banho metálico. Considerando-se o processo de Aspersão Térmica, no qual a velocidade do pó é um parâmetro 


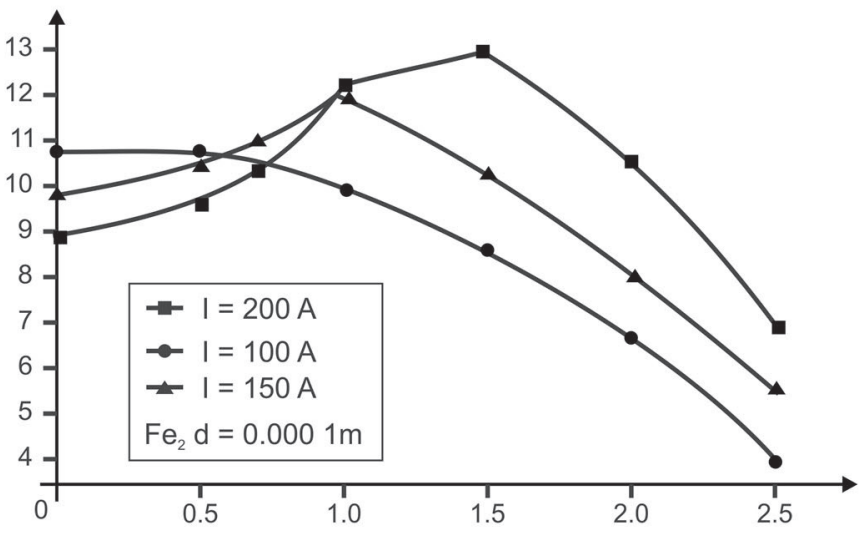

Distância do eixo axial (mm)

(a)
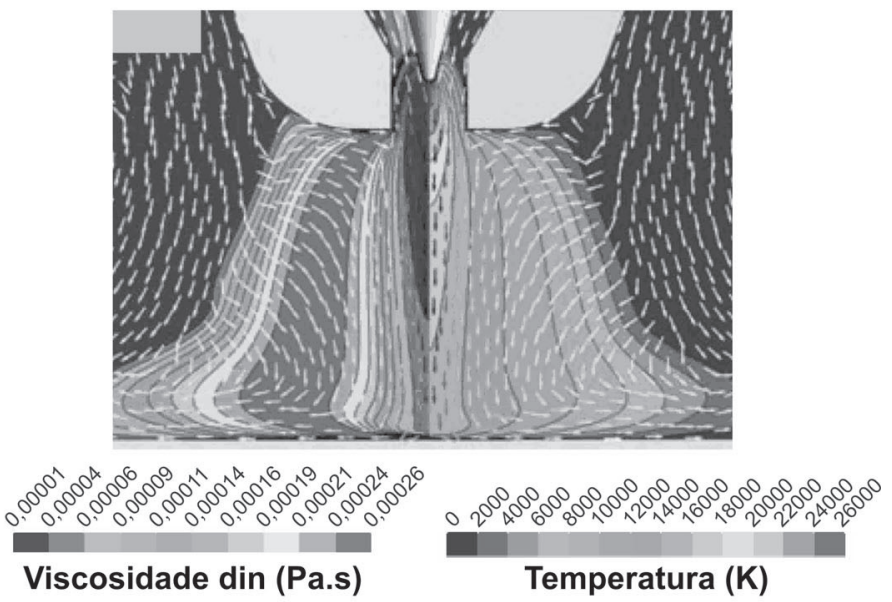

(b)

Figura 3. a) Distribuição radial da velocidade axial do pó em diferentes correntes de soldagem, adaptado do trabalho de Xibao et al. [7]; b) perfil de viscosidade calculado para soldagem plasma (adaptado do trabalho de Schnick et al. [12])
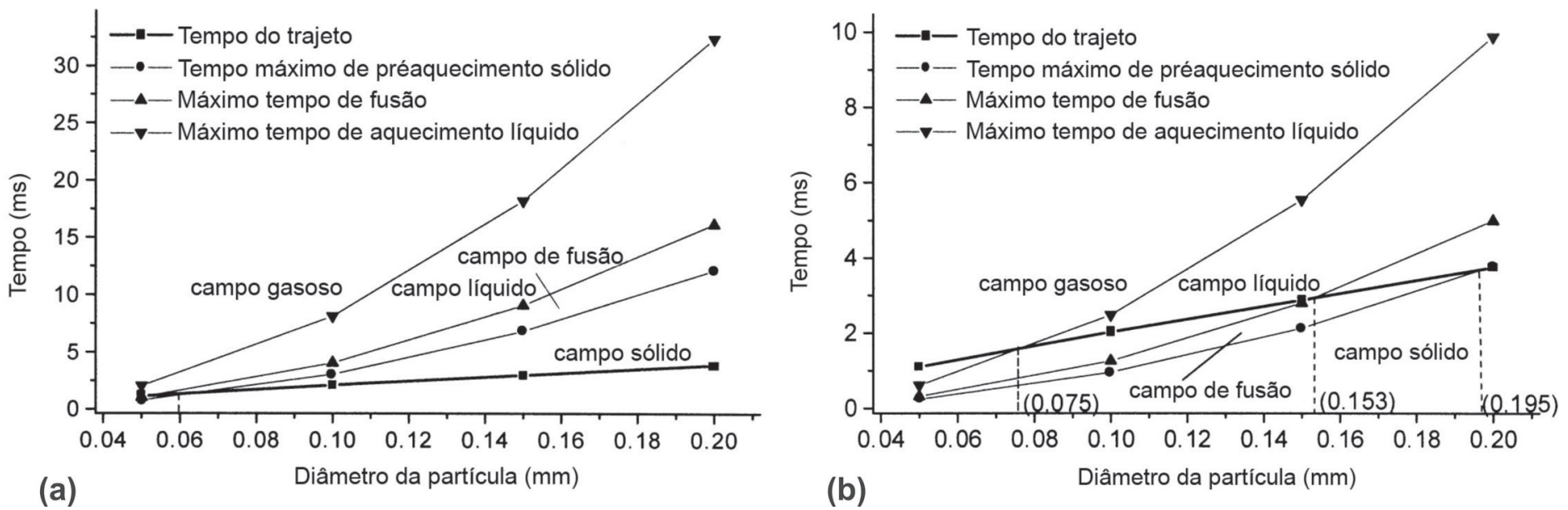

Figura 4. a) Comportamento térmico do pó para corrente de soldagem de $200 \mathrm{~A}$; b) comportamento térmico do pó para corrente de soldagem de 100 A (adaptado do trabalho de Xibao e Hua [8])

fundamental, conclui-se que esta hipótese é plausível.

Em [15], Wahl e Krauskopf afirmam que partículas de pó metálico adicionado se aquecem no arco acima do ponto de vaporização, formando vapores metálicos, os quais influem na troca de calor com o pó e nas propriedades do plasma. Além disso, formam depósitos que se condensam na superfície da tocha, sobre os cordões de solda e sobre o metal de base. Em peças grandes há o agravante de que maiores correntes são usadas, gerando, portanto, mais vapores. Sobre a tocha, podem gerar restrição do gás de proteção ou deflexão do jato plasma. As seguintes medidas são sugeridas pelos autores [15] para se evitar o problema este problema: design de tocha que resulte em fusão do pó na periferia do arco (vide Figura 3); assegurar partículas maiores que $60 \mu \mathrm{m}$ (limite similar ao colocado por Xibao e Hua [8]; $\mathrm{Ar}+\mathrm{H}_{2}$ (p. ex. $95 \% \mathrm{Ar}+5 \% \mathrm{H}_{2}$ ) como gás de proteção; maior DBP possível, de modo que a tocha esteja menos exposta aos vapores metálicos.

\section{Parâmetros do Processo PTA-P}

\subsection{Parâmetros Elétricos}

A potência do arco principal e o calor aportado à peça dependem fortemente da corrente do arco principal. Segundo Gebert [16], os defeitos de soldagem advêm essencialmente de irregularidades no calor aportado à peça e à poça fundida, ou seja, dependem da corrente. O trabalho não cita como é calculado este aporte térmico, mas menciona que correntes muito baixas acarretam em falta de fusão nas laterais do cordão e, por outro lado, correntes altas causam excesso de diluição. Marconi [17] mostra relação direta entre aporte térmico à peça e corrente do arco principal, medido por calorímetro.

$\mathrm{O}$ efeito nocivo de correntes demasiadamente altas citado por Huang et al. [18] é a tendência à formação de trincas, o que pode ser resolvido por oscilação da tocha de soldagem, mas não 
forneceu detalhes quanto ao tipo de trincas. Segundo Deuis et al. [5], o efeito nocivo seria a vaporização do pó e conseqüente redução do rendimento de deposição. Wahl e Krauskopf [15] consideram uma técnica em que o arco não transferido tem papel térmico ativo durante a soldagem. Ou seja, ele não apenas atua como arco piloto para ignição do arco principal, mas pode ter sua intensidade aumentada, de maneira a ter influência sobre o processo. Assim, estes autores analisam o efeito da corrente do arco principal dentro de uma proporcionalidade com o não transferido, de maneira que o incremento da proporção de energia do arco principal resulta em maior fusão do material de base. Ao contrário, maior proporção energética do arco não transferido propicia menor taxa de fusão do material de base.

O valor ótimo de corrente, segundo Deuis et al. [5], é o mínimo que resulta em máxima taxa de fusão de pó (e sua adequada deposição) para determinada taxa de alimentação. Um valor menor seria insuficiente para fundir o pó ou a peça e, nesse caso, haveria falha na formação do cordão. Estas premissas estão de acordo com as de Zhao et al. [19], quanto à formação de aglomerados de partículas não incorporadas à poça, devido a molhabilidade insuficiente.

De acordo com Bond et al. [20], valores de corrente do arco principal demasiadamente altas (cerca de $250 \mathrm{~A}$ ) causam maior oxidação sobre o cordão, redução da dureza, devida à maior diluição, e correntes demasiadamente baixas (cerca de $70 \mathrm{~A}$ ) causam descontinuidades no cordão de solda. Este trabalho se relaciona com a teoria anteriormente defendida por D'Oliveira et al. [21], quanto ao maior refino microestrutural obtido com material de adição em pó. Bond et al. [20] fazem referência à influência da intensidade de corrente no tamanho dos agregados de pó que agem como nucleantes na solidificação.

Marconi [17] constatou maior intensidade de calor transferido ao bico constritor com aumento da corrente do arco principal. Som [11] também observou uma relação direta entre a energia transmitida ao bico constritor e a corrente do arco principal ao medir por calorimetria o calor transferido ao bico, mas atribuiu esse comportamento ao aumento do diâmetro do arco com o aumento da corrente do arco principal.

A influência da corrente sobre o calor transferido ao pó é modesta. Como esperado, há uma relação direta entre os parâmetros (conforme item 2), mas o aumento da corrente resulta também em redução do tempo em que o pó fica no arco, recebendo calor deste [17]. Este efeito de compensação é mencionado também por Pavlenko [2].

\subsection{Vazões dos Gases do Processo}

Em termos de gases, aumento de vazão de gás de plasma resulta em maior rigidez do arco, mas o excesso traz maior penetração acompanhada de prejuízo ao acabamento superficial, de acordo com Huang et al. [18], e maior velocidade do jato plasma e turbulência, causando menor eficiência do gás de proteção, irregularidade no transporte do pó, poros e inclusão de óxidos, segundo Deuis et al. [5]. Com aumento da vazão de gás de plasma, Som [11] mediu maior calor transferido à peça e maior eficiência térmica e maior diluição. Marconi e Marconi [22] colocam a densidade de potência como principalmente dependente da vazão de gás de plasma.

Por intermédio de modelamento e simulação, Schnick et al. [23] avaliaram o comportamento da pressão do arco sobre a poça metálica para diferentes vazões de gás de plasma (Figura $5)$.

Segundo Marconi [17], em conseqüência da redução da vazão de gás de plasma se obtém aumento do calor transferido ao bico constritor (como relatado por Som [11]). Isto decorreria do fato de que o invólucro de gás frio que isola a superfície do orifício constritor também se reduz juntamente com a velocidade do gás de plasma [17].

Quanto ao gás de arraste, vazão excessiva ocasiona turbulência no arco, sucção de ar atmosférico e porosidade. Deuis et al. [5] sugerem que um valor acima do limite resulta no carreamento do pó além da coluna de plasma. Isto pode também contribuir para formação de partículas aglomeradas aderidas ao lado do cordão para ângulo de injeção de $30^{\circ}$, reportadas por Díaz [1], e uma vazão de gás de arraste de pó abaixo de 2,0 1/ min causou falhas no transporte. Diaz [1] verificou que o jato gás de arraste pode dificultar a abertura do arco principal. $\mathrm{O}$ problema foi solucionado pela implementação de um delay entre a abertura do arco principal e o início do fluxo de gás de arraste. A vazão de gás de arraste teve um efeito baixo (cerca de $1 \mathrm{~V}$, para variação de 0 a $6 \mathrm{l} / \mathrm{min}$ ) sobre a tensão do arco principal e apenas para injeção de pó a $30^{\circ}$. Som [11], utilizando um aparato calorimétrico e tocha com injeção interna de pó, verificou que o calor à peça e a eficiência térmica do processo caíram com maior vazão de gás de arraste.

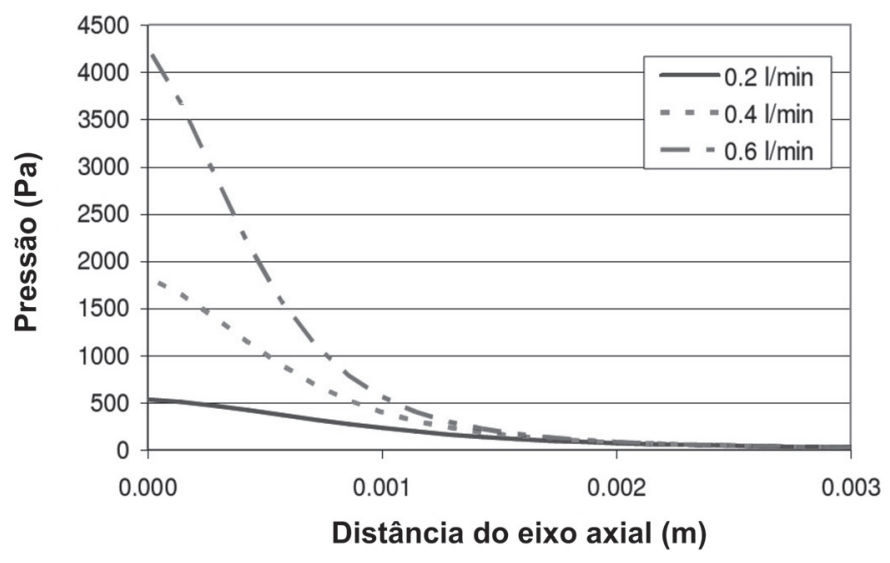

Figura 5. Relação entre pressão sobre a poça e vazão do gás de plasma (adaptado do trabalho de Schnick et al. [23])

\subsection{Alimentação de Material}

Matsuda et al. [24] relataram que um aumento na vazão de pó constringe e refrigera a coluna do arco, surgindo o efeito pinch térmico, resultando em penetração finger shape e maior profundidade, devido à maior temperatura e velocidade do plasma. Este mesmo efeito causa maior agitação da poça, expulsando gases e reduzindo porosidade.

Em revestimento com $\mathrm{Cu}$ em pó sobre liga de $\mathrm{Al}$ com alimentação excessiva de material, a fusão do metal de base não é suficiente [25]. Neste trabalho, Matsuda et al. [25] também 
observam maior penetração com o aumento da vazão de pó. Entretanto, o fenômeno é explicado pela crescente geração de calor advinda de reações de formação de compósitos. Ambos os trabalhos versaram primordialmente sobre questões metalúrgicas, sem muito detalhamento quanto ao processo em soldagem de Al.

No caso do aço se observa o efeito contrário: maior taxa de alimentação de pó ao arco resulta em menor diluição [1, 5, 26]. Segundo Bewley [27] e Milligan e Narasinham [28], a poça tem um efeito isolante térmico entre o arco e o substrato, pois no PTA-P, o arco se concentra sobre a poça e não sobre o material sólido. De acordo com Pavlenko [2] e empresa do setor [13], maior quantidade de pó alimentado retira mais calor da poça ao se incorporar a ela. Marconi e Marconi [22] têm outro ponto de vista sobre essa correlação: quanto maior a taxa de alimentação de pó, maior corrente do arco principal requerida e maior a diluição.

Hallen [26] obteve em suas investigações o gráfico da Figura 6, que inter-relaciona diluição e corrente do arco principal sob diferentes condições.

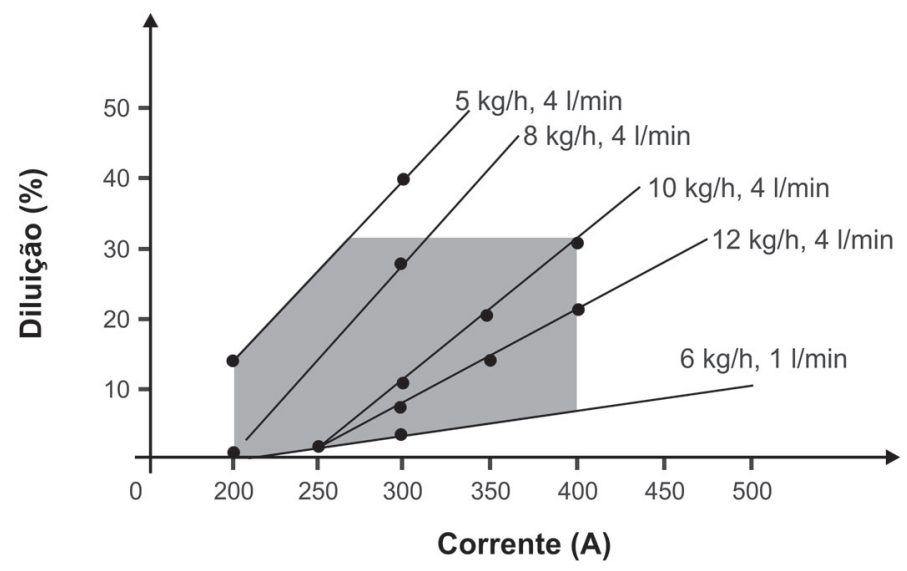

Figura 6. Diluição vs. corrente de soldagem em diferentes vazões de pó e de gás de plasma (adaptado do trabalho de Hallen et al.de [26])

\subsection{Parâmetros Geométricos (Tocha e Set-up)}

O diâmetro do orifício constritor tem papel importante no processo. Díaz [1] considera que, para menores diâmetros constritores, a corrente do arco principal deve ser reduzida, com a intenção de se evitar dano ao bico. Segundo Marconi [17], contraditoriamente, a redução do diâmetro constritor resulta em menos calor transferido ao bico constritor, pois há redução da superfície interna do orifício constritor aquecida por radiação.

Díaz [1] afirma que a largura do cordão está diretamente relacionada com o diâmetro do orifício constritor, no que concorda com Marconi [17], pelo aumento da seção térmica do jato plasma sobre a peça. Segundo Som [11], a atuação sobre o diâmetro constritor é a forma mais eficiente de se controlar o calor à peça. $\mathrm{O}$ mesmo autor afirma que maior calor é aportado à peça para menores diâmetros, devido à maior tensão do arco.

Um valor de $4,8 \mathrm{~mm}$ foi considerado máximo para o diâmetro constritor, sem que haja comprometimento da abertura do arco piloto por ignitor de alta freqüência [1].

Foram realizados por Hongying [6] ensaios de soldagem para verificar a influência do diâmetro do orifício constritor e da distância do ponto focal do pó até a poça, Lpp, na diluição e taxa de deposição. Houve maior taxa de deposição e maiores tensões de arco para menores diâmetros. Variando-se a Lpp de 8,0 mm para $10,0 \mathrm{~mm}$, houve redução na diluição de cerca de 7,5\% para menor que $5 \%$. A partir de $10,0 \mathrm{~mm}$ a diluição se manteve menor que $5 \%$. A maior Lpp resulta em maior tensão e maior potência, porém imagina-se que a atingível maior vazão de pó compense esse efeito e não se resulte em aumento da diluição. Quando a Lpp está ainda numa faixa até $8,0 \mathrm{~mm}$, a poça de fusão se encontra em contato com uma região mais quente plasma, resultando na maior diluição, sem o efeito de compensação. Pode-se levantar essa hipótese com base na observação realizada por Marconi [17], Figura 7.

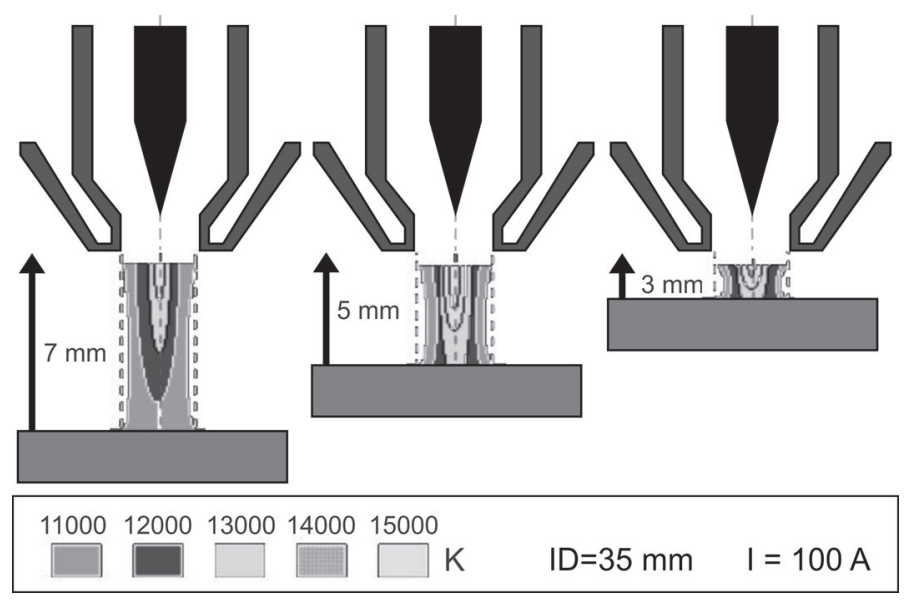

Figura 7. Regiões isotérmicas do arco, de acordo com variação da DBP (ID = diâmetro do orifício constritor, I = corrente do arco principal) (adaptado do trabalho de Marconi [17])

Segundo Deuis et al. [5], a faixa de operação da DBP é 10,0 $\mathrm{mm}$ a 15,0 mm, acima de cujo limite máximo o gás de proteção perde sua eficácia. Hallen [26], por outro lado, determinou uma DBP ótima de 20,0 mm em vazões de pó de $6 \mathrm{~kg} / \mathrm{h}$ a $10 \mathrm{~kg} / \mathrm{h}$. Hongyiang [6] obteve seus melhores resultados com DBPs maiores que 25,0 $\mathrm{mm}$. Apesar de se encontrar em uma faixa operacional de mais baixa energia e aporte de material, essa informação vai ao encontro dos resultados de Díaz [1], nos quais a penetração se reduziu com o aumento da DBP.

O recuo do eletrodo foi variado em por Díaz [1]. Em se comparando com 2,4 mm, 0,8 $\mathrm{mm}$ resultou em pior acabamento superficial para injeção externa de pó a $60^{\circ}$. Para injeção a $30^{\circ}$, não houve diferença quanto ao acabamento. Para ambos os ângulos, entretanto, houve menor eficiência de deposição para recuo de 0,8 mm. Apesar de o autor não ter idealizado uma hipótese, este fato pode se dever à menor potência do arco, à menor densidade de corrente ou ao desvio parcial das partículas de seu trajeto até poça (conforme aspectos vistos no item 2). 

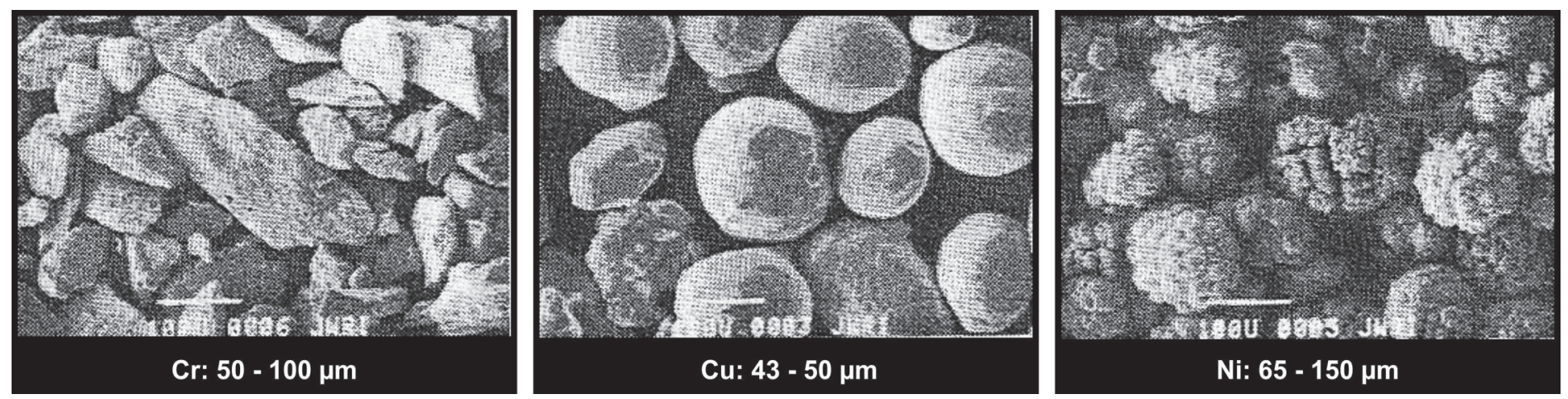

Figura 8. Tamanho de grão e morfologia dos pós metálicos (adaptado do trabalho de Matsuda et al. [25])

\section{Ligas Metálicas em Pó para Aplicação por PTA-P}

\subsection{Granulometria}

Ligas metálicas em pó para deposição por PTA-P devem apresentar determinadas características tecnológicas que tornem seu processamento viável. A primeira a ser colocada diz respeito à granulometria. Segundo Wahl e Krauskopf [15] para materiais ferrosos, deve ser dada preferência a partículas na faixa $60 \mu \mathrm{m}$ a $200 \mu \mathrm{m}$ que geram reduzidos vapores metálicos. Marconi [17] recomenda que se evitem tanto partículas muito grandes (acima de $150 \mu \mathrm{m}$ ), que não fundiriam por completo, como muito pequenas (abaixo de $63 \mu \mathrm{m}$ ), que são superaquecidas e, em decorrência, fortemente oxidadas. $\mathrm{Na}$ literatura se faz alusão a diferentes faixas granulométricas, porém com limites similares de cerca de 80 mesh a 325 mesh $(44 \mu \mathrm{m}$ a $180 \mu \mathrm{m})$. Deuis et al. [5] recomendam faixa entre $50 \mu \mathrm{m}$ e $150 \mu \mathrm{m}$, pois fora dela há problemas de alimentação. Segundo Draugelates et al. [29], a justificativa é um comportamento contínuo e repetitivo da alimentação, mas a faixa recomendada é $100 \mu \mathrm{m}$ a $200 \mu \mathrm{m}$. Na aplicação prática de Milligan e Narasimhan [28], a granulometria utilizada foi acima de 60 mesh. White et al. [30] aplicaram faixa granulométrica de 200 mesh a 325 mesh (45 $\mu \mathrm{m}$ a $75 \mu \mathrm{m}$ ). De fato, Xibao e Hua [8] sugerem que, para a seleção tanto dos parâmetros de soldagem, como também do tamanho das partículas, o comportamento térmico de cada pó sob condições de soldagem PTA-P deve ser analisado.

\subsection{Processos de Fabricação e Morfologia}

No que tange ao processo de fabricação, os mais relevantes são a atomização em bocal a dois fluidos e o trituramento. Existem, no entanto, outras técnicas, como a fusão em cadinho frio por levitação eletromagnética. A técnica de atomização em bocal a dois fluidos consiste na fusão da liga em um cadinho, seguida pela queda do metal líquido por um ou mais bocais verticais. Esse veio líquido é rasgado por um jato de ar, água, vapor ou gases. As gotas assim formadas solidificam durante a queda. Depois de secas, são peneiradas para separação. A forma e distribuição dimensional das partículas, assim como a densidade aparente, podem ser reguladas pelos parâmetros de atomização, e se podem adicionar componentes tensoativos, estimulando a formação esférica [17].
A Figura 8 mostra os pós de $\mathrm{Cr}, \mathrm{Cu}$ e $\mathrm{Ni}$ aplicados em revestimentos sobre substrato à base de $\mathrm{Al}$. $\mathrm{O}$ pó de Cr é fabricado por trituramento, enquanto os de $\mathrm{Ni}$ e Cu são atomizados [25].

Pós atomizados em água tem mais cantos e, assim, absorvem mais umidade $([25,31])$ e fluem pior que pós atomizados em gás inerte, de forma esférica [5, 17, 31], além de apresentarem maior oxidação no processo de fabricação [17]. Em divulgação técnica [32], relativa à deposição de partículas duras sobre matriz dútil, se reporta que a forma esférica permite aglomeração mais compacta de carbonetos aportados. Além disso, partículas duras angulosas sob fadiga tendem a precipitar trincas no na matriz do depósito. Soma-se a isso o fato de que os cantos de partículas angulosos se fundem facilmente, formando compostos frágeis que também fomentam formação de trincas. A forma esférica, assim, provê maior resistência ao impacto.

Dilthey e Kabatnik [33] relatam dificuldades para soldagem com pós atomizados em água, devido à forte geração e emissão de vapores. Pós triturados acarretam em problemas semelhantes, segundo Marconi [17]. Em resultados de Gebert et al. [16], pós atomizados em gás inerte obtiveram soldas sem defeitos e com baixa diluição. Já o pó oriundo de atomização em água não permitiu cordões livres de porosidade.

No contexto do trabalho de Matsuda et al. [25], que aplicou substrato de alumínio, foi investigado o efeito da morfologia do pó na geração de porosidade. Foi executada a análise de gás residual nos poros, através da qual foram encontrados resíduos de $\mathrm{CO}_{2}, \mathrm{~N}_{2}, \mathrm{H}_{2} \mathrm{O}$ e $\mathrm{H}_{2}$. Conclui-se que o maior agente causador de porosidade é o $\mathrm{H}_{2}$. Sua origem são materiais orgânicos e água absorvidos no metal de base e de adição. E o estudo conclui que a origem dominante é a água $\left(\mathrm{H}_{2} \mathrm{O}\right)$ absorvida na superfície do pó. Esta afirmação é apoiada pela investigação da morfologia dos pós utilizados: esférico apresentou baixa porosidade; angulosos e, portanto, com vários sítios para retenção de $\mathrm{H}_{2} \mathrm{O}$, apresentaram elevada porosidade.

Alguns trabalhos recomendam, neste contexto, procedimentos de secagem do pó antes da solda [25, 31,34].

\subsection{Composição Química}

Em relação à composição química, é apresentada por Wahl e Krauskopf [15] uma lista de ligas aplicadas em PTA-P (complementada por listas de outros trabalhos): ligas de alumínio (também citadas por Kabatnik [35]); ferro e suas ligas; cobalto 

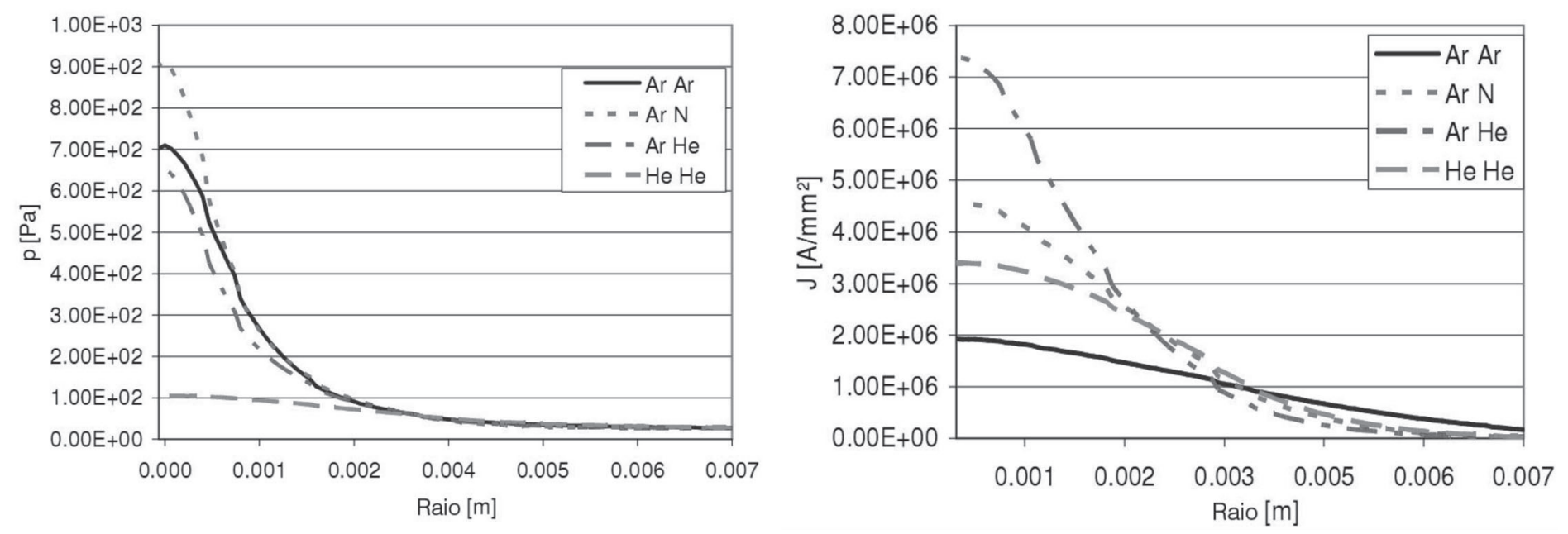

Figura 9. Pressão do arco e a densidade de corrente, para diferentes gases de proteção (adaptado do trabalho de Schnick et al. [23])

e suas ligas (também citados por Bewley [27] e Desir [36]); cobre (também citado por Matsuda et al. [25] e Bewley [27]); bronze (também citado por Pekarek [37], sobre ferro fundido); molibdênio e suas ligas; níquel e suas ligas (também citados por Matsuda et al. [25] e Bewley [27], sobre alumínio); titânio e suas ligas; carboneto de tungstênio em matriz metálica (também citado por Draugelates [29]); zircônio e suas ligas.

Este trabalho [15] também chama atenção para a impossibilidade de utilização de pós de baixo ponto de vaporização, como Zinco, por causa das altas temperaturas do plasma. Em [27], Bewley estende a limitação a cerâmicas, óxidos, materiais refratários, materiais muito reativos como titânio, e alumínio. Quanto ao último material, no entanto, a informação vai de encontro à experiência de outros autores, como Wahl e Krauskopf [15] e [35]. Além disso, outros trabalhos da literatura abordam aplicações de cerâmica $[5,8,10]$, e ligas de Vanádio [16, 38].

\subsection{Escoabilidade}

A propriedade chamada escoabilidade possui influência significativa nas características da alimentação. Sua unidade é s/50g e equivale ao tempo necessário para que $50,0 \mathrm{~g}$ de pó escoe através de um funil padronizado [17].

A geometria do pó influencia a escoabilidade, tendo reflexos sobre a taxa de alimentação $[17,28]$, de modo que pós esféricos têm melhor escoabilidade [5, 17]. Para granulometrias muito baixas, entretanto, mesmo os esféricos possuem escoabilidade reduzida [17]. Ribeiro [4] introduz o conceito de "ângulo de empilhamento" como indicativo da capacidade do pó em fluir (que ele chama em seu texto de "escoabilidade"), mas não fornece a metodologia de medição e princípios físicos.

\section{Gases do Processo PTA-P}

O processo de soldagem PTA-P aplica, fundamentalmente, três fluxos de gás: gás de plasma, gás de proteção e gás de arraste de pó. A composição dos gases pode ser manipulada para obtenção de diferentes temperaturas e entalpias no plasma, o que torna possível influenciar segundo Wahl e Krauskopf [15], a densidade de energia, a penetração e a taxa de fusão. Espera-se encontrar influência também sobre a diluição e sobre o aporte de calor à peça, advindo tanto de aquecimento anódico, como de convecção e energia de recombinação de gases moleculares.

Quanto à escolha dos gases ou misturas a se utilizar em revestimentos soldados por PTA-P existe uma profusão de opções. A decisão depende dos materiais envolvidos e da tarefa a ser realizada. $O$ gás de plasma deve ser inerte, sendo usualmente escolhido o Ar. Tur [39] recomenda a mistura Ar 60 \% / He 40 $\%$, para proteger as superfícies inferiores da tocha.

Argônio e misturas de argônio e hidrogênio são comumente mencionadas como gás de proteção $[5,15,17,27,36]$. Marconi e Marconi [22] reportam que uma porcentagem de $2 \%$ a $8 \%$ de $\mathrm{H}_{2}$ é responsável por promover uma solda esteticamente mais limpa, devido à propriedade redutora deste gás. Segundo Huang et al. [18], o uso de Ar resulta em menor perda de elementos de liga no depósito. Todavia, o He também aparece em algumas pesquisas $[5,17,35]$.

Quanto à influência do gás de proteção na pressão do arco sobre a poça e na densidade de corrente, Schnick et al. [23], através de modelamento e simulação, concluem que, devido ao alto calor específico e alta condutividade térmica do $\mathrm{N}_{2}$ e devido ao alto potencial de ionização e alta condutividade térmica do He, esses gases provocam uma $\square$ focalização $\square$ do arco pelo resfriamento da superfície externa do mesmo. No entanto, isso não se traduz necessariamente em maior pressão sobre a poça e maior penetração, como se observa na Figura 9. Para o He, a viscosidade é alta para temperaturas entre $10000 \mathrm{~K}$ e 20000 $\mathrm{K}$, causando baixa velocidade do jato plasma e menor pressão sobre a poça. As condições anteriores eram relativas ao processo Plasma (PAW), servindo como base para o conhecimento do comportamento do arco. Para o PTA-P em específico, a Figura 10 mostra o estrangulamento das isotermas próximo à poça, em decorrência da injeção de gás de arraste [40].

Como gás de arraste, o mais citado é $\operatorname{Ar}[15,17,18,22,27]$, mas também se utilizam $\mathrm{N}_{2}[15]$, He [27, 28] e mistura de $\mathrm{Ar}$ e 
$\mathrm{H}_{2}$ [5]. Misturas com $\mathrm{H}_{2}$ e $\mathrm{He}$ ou He puro são recomendadas em [41], resultando em melhor acabamento. O autor deixa claro que se podem manipular as misturas, as adequando para aplicações com ligas de difícil soldabilidade, que possuem baixa fluidez.

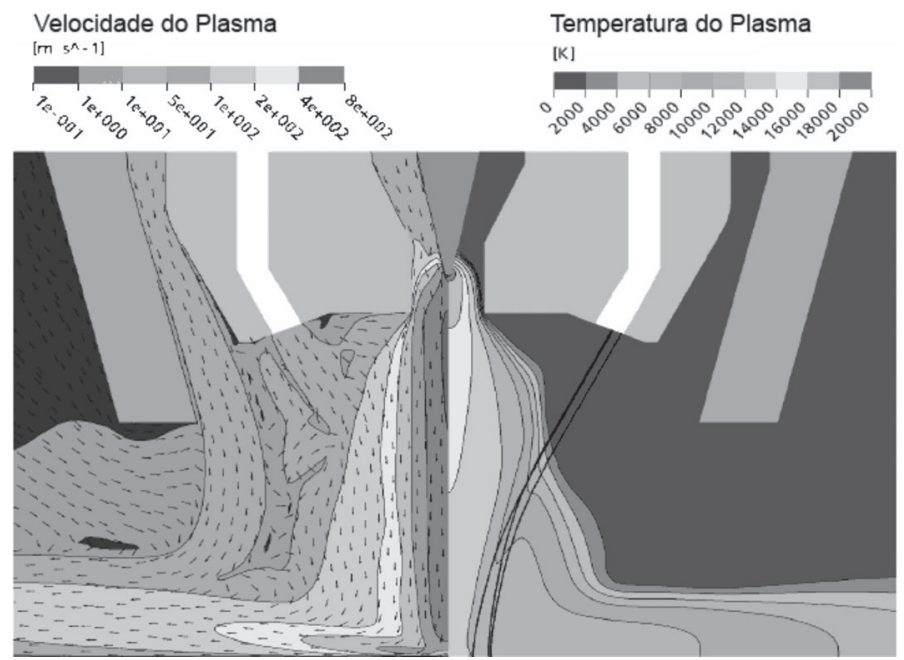

Figura 10. Modelamento da tocha, velocidades e temperatura do plasma do processo PTA-P (adaptado do trabalho de Schnick et al. [40])

\section{Considerações Finais}

Apesar da dificuldade tecnológica de se observar e medir fenômenos que ocorrem durante a transferência do material de adição em pó até sua efetiva incorporação pela poça metálica no processo PTA-P, inúmeros autores abordaram este tema, lançando mão de técnicas numéricas, modelamento e simulação, assumindo determinadas condições de contorno. Devido a diferentes metodologias, sofisticação ferramental, assim como pela admissão de condições de contorno muito simplificadas ou relativamente distantes da situação real, os resultados e conclusões divergem. As informações de maior importância quanto ao comportamento termo-cinético do pó são o estado em que as partículas chegam à poça e sua trajetória espacial. A temperatura, velocidade de colisão e a entalpia das partículas determinam as condições de troca térmica entre as mesmas e a poça metálica, impactando a formação da microestrutura, a homogeneidade da distribuição de composição química, temperatura da poça metálica, molhabilidade e diluição. Neste sentido, há autores que afirmam que as partículas impingem a poça já em estado fundido, enquanto outros afirmam que isso ocorre em um estado semifundido. Levando em conta as metodologias e técnicas empregadas, considera-se que a segunda hipótese é a mais provável. A trajetória percorrida pelas partículas também tem sido objeto de estudo, sendo que não somente a geometria da tocha, mas também as propriedades dos gases apresentam grande influência. Desta revisão se obtiveram importantes informações que têm subsidiado o projeto de tocha de soldagem para aplicações fora de posição, cujo desenvolvimento será descrito em artigo futuro.

Em se tratando de parâmetros de soldagem, além do conhecimento tradicional do efeito da corrente de soldagem, extrai-se das informações adquiridas a conclusão de que são importantes as interações entre as variáveis, as quais não são lineares. A corrente, atrelada a outras condições de soldagem, determina a potência e a distribuição térmica do arco. Alterações nestas características alteram, como em outros processos, propriedades relacionadas à transferência de calor e, adicionalmente no PTA-P, as condições de arraste e aquecimento do pó. No processo PTA-P, deve-se considerar com atenção o efeito da corrente sobre a tocha, mais especificamente o orifício constritor, os canais de alimentação de pó e o circuito de refrigeração, os quais devem operar em condições que mantenham sua integridade, evitando perturbações no arco e na injeção de material.

Em termos dos valores de vazão dos gases do processo, a do gás de plasma é a mais determinante para o resultado da solda. No entanto, o gás de arraste também apresenta influência apreciável na forma geométrica do arco e na geometria do cordão. Já a vazão do gás de proteção, dentro de limites operacionais, não apresenta influência tão determinante sobre o depósito. Em exercendo influência sobre o perfil de temperatura do arco, a vazão dos gases também atua sobre o comportamento termo-cinético das partículas adicionadas. A taxa de alimentação de material tem efeitos notados primordialmente na diluição e geometria do cordão, que não seguem necessariamente o mesmo comportamento para diferentes materiais.

Os parâmetros construtivos da tocha, como diâmetro do orifício constritor e o ponto focal do pó, atuando juntamente com a DBP, têm impacto no processo através de efeitos como variação da potência de arco e conseqüentemente no perfil do cordão, e aceleração e aquecimento das partículas.

Considerou-se importante o estudo das características do material particulado aplicado como material de adição no processo PTA-P. Não somente sua composição química, mas sua morfologia e faixas granulométricas apresentam fundamental influência sobre o processo. A capacidade de dosagem e alimentação é impactada pela escoabilidade do pó, que, por sua vez, depende da morfologia e faixa granulométrica. $O$ processo de fabricação do material de adição determina estas características, sendo que a atomização a gás permite controle da faixa granulométrica e resulta em partículas próximas à esfericidade, com melhor desempenho de alimentação e fusão do que partículas alongadas ou poligonais. Pós triturados, com vários ângulos e cantos vivos, têm também maior tendência a absorção de umidade, podendo contaminar o metal de solda. Não obstante, é interessante uma configuração de sistema PTA-P que possibilite uso de pós que fujam das características ideais, pois é comum a indisponibilidade de determinadas ligas ou elementos nestas condições.

Finalmente, foram investigadas implicações oriundas das propriedades dos gases. Em se tratando da Soldagem PTA-P, além de influência na potência do arco, na capacidade de transmissão de calor, na estabilidade do arco e na facilidade de ignição do arco, têm grande importância também as propriedades de arraste das partículas de pó e conseqüentemente, seu direcionamento, aceleração e aquecimento após injeção no arco. Portanto, a seleção dos gases ou misturas gasosas deve 
levar em consideração diferentes condições de soldagem. No processo PTA-P, que utiliza três fluxos de gás, a janela de possibilidades é ampliada, pois as características termocinéticas e eletromagnéticas do plasma resultam da interação entre os gases. Não se encontraram na literatura incursões a este respeito, tendo este fato como provável causa a complexidade de análises. No entanto, considera-se que tecnologias atuais de modelamento e simulação, integradas a sistemas especiais de monitoramento (PIV, filmagem térmica, etc.) possam vir a gerar conhecimento básico relevante sobre o processo.

\section{Referências Bibliográficas}

[1] DÍAZ, V. M. V., Inovação do Equipamento e Avaliação do Processo Plasma de Arco Transferido Alimentado com Pó (PTAP) para Soldagem Fora de Posição. 2005, 198 f. Tese (Doutorado em Engenharia) - Universidade Federal de Santa Catarina, Florianópolis

[2] PAVLENKO, A. Neue Kentnisse über Phylikalische Grundlagen des Plasma-Pulver-Auftragschweißens als Basis für die Prozeßsteuerung. 1996. 118 f. Tese (Doutorado em Engenharia) - Rheinisch-Westfälisch Technisch Technisch Hochschule Aachen

[3] MENON, R., MOSIER, W. C., Stainless Steel with Improved Weldability and Cavitation Resistance, CONSOLDA, 1996

[4] RIBEIRO, H. O. Desenvolvimento de Ligas para Revestimentos por PTA Resistentes à Cavitação. 2007. 167 f. Tese (Doutorado em Engenharia) - Universidade Federal de Santa Catarina

[5] DEUIS, R. L. et al. Metal-matrix composite coatings by PTA surfacing. Composites Science and Technology, v.58, n. 2, p. 299-309, 1998

[6] HONGYING, W. et al. Investigation on the deposition rate and the dilution ratio of plasma surface welding. China Welding, v.11, n.1, p.55-58, mai. 2002

[7] XIBAO, W.; WENYUE, Z. The Theoretical Evaluation of Powders Transportation in Plasma Transferred-arc Space under Coaxial Powder Feeding Condition. China Welding, v.10, n.2, p. 104-110. nov. 2001

[8] XIBAO, W.; HUA, L. Metal Powder Thermal Behavior during the Plasma Transferred-arc Surfacing Process. Surface and Coatings Technology, v. 106, n. 1-2, p. 156-161. ago. 1998

[9] FAUCHAIS, P.; VARDELLE, A. Thermal Plasmas. IEEE Transactions on Plasma Science, v.25, n.6, dez. 1997

[10] XIBAO, W. et al. The Powder's Thermal Behavior on the Surface of the Melting Pool During PTA Powder Surfacing. Surface and Coatings Technology, v. 201, n. 6, p. 2648-2654. dez. 2006

[11] SOM, A. I. New Plasma Torches for PTA-surfacing. Artigo disponível em www.plasma-master.com.ua. Acesso em fev. 2006

[12] SCHNICK, M. et. al. Numerical Investigations of the Influence of Design Parameters, Gas Composition and
Electric Current in Plasma Arc Welding (PAW). TU Dresden. Dresden, dez. 2009

[13] Cosima website. Disponível em www.cosima.com. Acesso em mar. 2009

[14] KIM, H.-J; KIM, Y.J. Wear and Corrosion Resistance of PTA Weld Surfaced Ni and Co Based Alloy Layers. Surface Engineering, v.15, n.6, p. 495-501. 1999

[15] WAHL, W.; KRAUSKOPF, F. Plasma-arc Powder Surfacing of Ferrous Materials. Welding and Cutting, n. 2, p. 15-16. Düsseldorf, fev. 1993

[16] GEBERT, A. et al. Plasma-Pulver-Auftragschweissen. Oberflächentechnik, n.1, p. 56-60. München, 1996

[17] MARCONI, M. I Riporti duri con polveri saldate con il processo P.T.A. (Plasma ad Arco Trasferito). Livro Online (www.plasmateam.com), 320 p. 2002.

[18] HUANG, X. et al. Applications of PTA Powder Welding in Petroleum Chemical Industry. Proceedings of the $15^{\text {th }}$ International Thermal Spray Conference, p. 1013-1017. Nice, mai. 1998

[19] ZHAO, C. et al. Non-transferred Arc Plasma Cladding of Stellite Ni60 Alloy on Steel. Surface and Coatings Technology, v.155, n. 1, p. 80-84. jun. 2002

[20] BOND, D.; et al. Efeito da Intensidade de Corrente nas Características de Revestimentos Soldados com Material de Adição Atomizado. Anais do Congresso Brasileiro de Engenharia de Fabricação III COBEF. Joinville, 2005

[21] D'OLIVEIRA, A. S. C. M.; PAREDES, R.S.C.; SANTOS, R. L. C. Pulsed Current Plasma Transferred Arc Hardfacing. Journal of Materials Processing Technology, v. 171, n. 2, p. 167-174. jan. 2006

[22] MARCONI, M.; MARCONI, B. Powder Plasma Arc Welding on Thick Walled Pipes. International Institute of Welding, 16 p., Paper 11. 2005

[23] SCHNICK, M. et al. Simulation von Plasmalichtbögen. Artigo do DFK 2006, 10 p.. Dresden, mar. 2006

[24] MATSUDA, F. et al. Carbide Addition on Aluminium Alloy Surface by Plasma Transferred Arc Welding Process. Transactions of JWRI, Welding Research Institute of Osaka University, v.19, n.2, p. 241-247. Osaka, 1990

[25] MATSUDA, F. et al. Formation of Thicker Hard Alloy Layer on Surface of Aluminum Alloy by PTA Overlaying with Metal Powder. Transactions of JWRI, Welding Research Institute of Osaka University, v.20, n.1, p. 89. Osaka, 1991 [26] HALLEN, H. et al. Plasma Transferred Arc Surfacing with High Deposition Rates. Proceedings of the $4^{\text {th }}$ National Thermal Spray Conference. p. 537-539. Pittsburg, mai. 1991 BEWLEY, J.G. Plasma-transferred-arc Wearfacing. Tooling \& Production, p. 54-55. dez. 1980

[27] MILligAN, J.; NARASIMHAN, S. A Powder Fed Plasma Transferred Arc Process for Hard Facing Internal Combustion Engine Valve Seats. SAE Technical Paper Series, Congress and Exposition Cobo Hall, 12 p. Detroit, fev. 1980 [28] DRAUGELATES, U. et al. HochleistungsPlasmapulverauftragschweißen mit Duplex-stählen. 
Schweissen \& Schneiden, n. 5, p. 245-251. Düsseldorf, mai. 1999

[29] WHITE, R. A., et al. Underwater Welding with Laser and Plasma Arc Welding. Welding Journal, v. 76, n. 1, p. 5761. Miami, jan. 1997

[30] BEWLEY, J.G. High Production Hard Surfacing with Versatile Metal Powders. Welding Design \& Fabrication. p. 70-71. abr. 1978

[31] Technogenia website. Disponível em http://www. technogenia.de. Acesso em fev. 2012

[32] DILTHEY, U.; KABATNIK, L. Zentrale Pulverzufuhr beim Plasma-Pulverauftragschweissen. Schweissen \& Schneiden, n. 12, p. 766-771. Düsseldorf, dez. 1998

[33] SUN, Z.; HUANG, Z.H. Micro-PTA powder cladding on a hot work tool steel. Int. J. of Materials and Product Technology, v.13, ns. 3-6, p. 146-154, 1998

[34] KABATNIK, L. Plasma-Pulver-Schweißen Verschleißbeständiger Schichten auf Aluminiumwerkstoffe. 2002. 128 f. Tese (Doutorado em Engenharia) - RheinischWestfälisch Technisch Technisch Hochschule Aachen [35] DESIR, J.L. Plasma Arc Coatings Combat Component Wear. Welding and Metal Fabrication, p. 219-222. jun. 1983 PEKAREK, M., Eutronic GAP Plasma Schweißtechnik. Apresentação no DFK (Dresdner Fügetechnisches Kolloquium) 2006. 19 p.. Dresden, mar. 2006

[36] GEBERT, A. et al. Verlängerung der Standzeit von Messern und Verschleissleisten durch Plasma-Pulver-Auftragschweissen von hochkarbidhaltigen Eisenwerkstoffen. Wochenblatt für Papierfabrikation, n. 19, p. 946-949. 1998

[37] TUR, M. Method for Plasma Transferred Arc Welding. Depósito de patente n. 8903522.4. UK Patent Office, ago. 1990 SCHNICK, M. et al. Der Lichtbogen in der Prozesssimulation-die realen Möglichkeiten zum Beispiel für die Brennerentwicklung. Apresentação em Seminário no SLV München. 33 p.. Munique, 27/03/2007

[38] RAGHU, D.; WEBBER, R. PTA Proves its Worth in HighVolume Hardfacing Jobs. Welding Journal, v. 75, n. 2, p. 34-40.

Miami, fev. 1996 